\title{
Group B Streptococcus detection in pregnant women via culture and PCR methods
}

\author{
Cláudia Wollheim ${ }^{[1]}$, Rosa Dea Sperhacke ${ }^{[2]}$, Sabrina Kahler Ribeiro Fontana ${ }^{[3]}$, \\ Andréa Cristina Vanni ${ }^{[2]}$, Sérgio Kakuta Kato ${ }^{[2],[4],[5]}$, Patricia Regina de Araújo ${ }^{[1],}$ \\ Afonso Luis Barth ${ }^{[6]}$ and José Mauro Madi ${ }^{[3]}$
}

\begin{abstract}
[1]. Laboratório de Microbiologia Clínica, Universidade de Caxias do Sul, RS, Brasil. [2]. Laboratório de Pesquisa em HIV/AIDS, Universidade de Caxias do Sul, RS, Brasil. [3]. Departamento de Ginecologia e Obstetrícia, Hospital Geral, Universidade de Caxias do Sul, RS, Brasil.

[4]. Universidade Federal de Ciências da Saúde de Porto Alegre, RS, Brasil. [5] Pontifícia Universidade Católica do Rio Grande do Sul, Porto Alegre, RS, Brasil. [6] Universidade Federal do Rio Grande do Sul, RS, Brasil.
\end{abstract}

\begin{abstract}
Introduction: Group B Streptococcus (GBS), a source of neonatal infection, colonizes the gastrointestinal and genitourinary tracts of pregnant women. Routine screening for maternal GBS in late pregnancy and consequent intrapartum antibiotic prophylaxis have reduced the incidence of early-onset GBS neonatal infection. The aim of this study was to evaluate the performance of PCR, compared to culture (gold standard), in GBS colonization screening of pregnant women, and to establish the prevalence of GBS colonization among this population. Methods: Vaginal introitus and perianal samples were collected from 204 pregnant women, between the $35^{\text {th }}$ and $37^{\text {th }}$ weeks of pregnancy, at the Obstetrics and Gynecology Unit of the University of Caxias do Sul General Hospital between June 2008 and September 2009. All samples were cultured after enrichment in a selective medium and then assayed by culture and PCR methods. Results: The culture and PCR methods yielded detection rates of vaginal/perianal GBS colonization of $22.5 \%$ and $26 \%$, respectively (sensitivity $100 \%$; specificity $95.6 \%$; positive and negative predictive values $86.8 \%$ and $100 \%$, respectively). A higher prevalence of GBS colonization was detected in the combined vaginal and perianal samples by both culture and PCR assay analyses. Conclusions: PCR is a faster and more efficient method for GBS screening, allowing for optimal identification of women who should receive intrapartum antibiotic prophylaxis to prevent newborn infection.
\end{abstract}

Keywords: Group B Streptococcus. Pregnant women. Culture. PCR.

\section{INTRODUCTION}

Neonatal infections with Streptococcus agalactiae, commonly referred to as Group B Streptococcus (GBS), are associated with high morbimortality ${ }^{1,2}$. In pregnant women, GBS colonizes the bowels and/or the vagina without eliciting clinical symptoms. This colonization is a dynamic condition and represents the main risk factor for early neonatal infection. Notably, the international literature reports maternal GBS colonization rates of $6.5-36.0 \%$ in Europe ${ }^{6,7}, 10.0-30.0 \%$ in North America ${ }^{2,8}, 16.5-31.6 \%$ in African countries ${ }^{9}$, and 1.4$36.7 \%$ in South America, including Brazil ${ }^{10-13}$, Chile ${ }^{14}$, $\mathrm{Peru}^{15}$, and Argentina ${ }^{16}$.

The first guidelines for the prevention of GBS infection by maternal intrapartum antibiotic prophylaxis were created in $1966^{1,3,4}$. After the initiation of such strategies, an $80 \%$ reduction in the incidence of neonatal GBS disease was

Corresponding author: Dra. Cláudia Wollheim.

e-mail: cwollhei@ucs.br

Received 4 November 2016

Accepted 23 March 2017 observed in the United States, yielding a reported incidence of 7,500 cases per year. This incidence was reduced even further following the Centers for Disease Control and Prevention (CDC)-recommended enactment of universal screening through culturing of pregnant women in the 2002 consensus revision ${ }^{5}$. Nevertheless, GBS disease persists, and is the main infectious cause of newborn morbimortality in the United States.

Revised CDC guidelines for the prevention of early-onset GBS disease (2010) recommend universal culture-based screening of all pregnant women at $35^{\text {th }}$ and $37^{\text {th }}$ weeks of pregnancy to identify those who should receive prophylactic intrapartum antibiotic treatment ${ }^{2}$. Although the $\mathrm{CDC}$ guidelines indicate culture as the gold standard method for GBS detection, these same guidelines include expanded laboratory methods for detecting this organism. In particular, polymerase chain reaction (PCR)-based assays comprise an additional option for the rapid detection of GBS colonization ${ }^{2,8}$.

The aim of this study was to evaluate the performance of a PCR assay, compared to the gold standard culture method, in screening for GBS colonization of pregnant women, and to examine the prevalence of GBS colonization among this population. 


\section{METHODS}

\section{Procedures}

Vaginal introitus and perianal samples were collected from 204 pregnant women during visits to the Obstetrics and Gynecology Unit of the University of Caxias do Sul General Hospital between June 2008 and September 2009. Sociodemographic, obstetric, and relevant perinatal event data were collected from each patient, including maternal age, parity, incidence of previous abortions, and clinical intercurrences during pregnancy. Samples were collected using sterile swabs without using a speculum, according to CDC guidelines ${ }^{5}$, during physical examination of the women between the $35^{\text {th }}$ and $37^{\text {th }}$ weeks of pregnancy. This study was approved by the ethics committee of the University of Caxias do Sul General Hospital, and all patients provided written informed consent prior to inclusion in the study.

\section{GBS Culture}

For GBS culture, swabs were used to inoculate two culture tubes containing Todd-Hewitt broth (Oxoid, Hampshire, United Kingdom) supplemented with gentamicin $(8 \mu \mathrm{g} / \mathrm{mL})$ and nalidixic acid $(15 \mu \mathrm{g} / \mathrm{mL})$. The cultures were incubated at $33-37^{\circ} \mathrm{C}$ for 18 to $24 \mathrm{~h}$, then streaked on $5 \%$ sheep blood agar plates and incubated at $33-37^{\circ} \mathrm{C}$ for 18 to $24 \mathrm{~h}$ in a $5 \% \mathrm{CO}_{2}$ atmosphere. $\beta$-hemolytic and non- $\beta$-hemolytic colonies were subcultured in Todd-Hewitt broth and subjected to CAMP (Christie, Atkins, Munch, Pertesen) ${ }^{17}$ test and latex agglutination analyses to confirm that they were GBS ${ }^{5}$.

\section{PCR assay}

For PCR analysis, 3.0-mL samples of cultures grown in Todd-Hewittt broth were harvested by centrifugation. Two $1.5 \mathrm{~mL}$ aliquots of culture were centrifuged at $13,000 \mathrm{rpm}$ for $3 \mathrm{~min}$ at room temperature. The resulting precipitates were resuspended with $1 \times$ Phosphate Buffered Saline $(\mathrm{PBS})$ solution and resuspended in TE buffer [10mM Tris- $\mathrm{HCl}(\mathrm{pH} 7.5)$, $0.1 \mathrm{mM}$ Ethylenediaminetetraacetic acid - (EDTA)]. Genomic deoxyribonucleic acid (DNA) was then extracted by thermal lysis, as described by De Paris et al. ${ }^{18}$, and stored at $-80^{\circ} \mathrm{C}$ prior to use.

The PCR assay was standardized to a volume of $25 \mu \mathrm{L}$ containing $1.5 \mathrm{U}$ of Taq DNA polymerase (Super Therm, BioAmerica, Inc.); $0.4 \mu \mathrm{M}$ each GBS-specific primers atrF (5'-CGATTCTCTCAGCTTTGTTA-3') and atrR (5'-AAGAAATCTCTTGTGCGGAT-3'); $2.5 \mu \mathrm{L}$ of $10 \times$ buffer containing $15 \mathrm{mM} \mathrm{MgCl} 2 ; 2.5 \mu \mathrm{L}$ of dNTP with $0.2 \mathrm{mM}$ each nucleotide; and $5 \mu \mathrm{L}$ of each DNA sample. The conditions for the PCR were as follows: $94^{\circ} \mathrm{C}$ for $1 \mathrm{~min}$, followed by 30 cycles divided into denaturation $\left(94^{\circ} \mathrm{C}, 1 \mathrm{~min}\right)$, annealing $\left(55^{\circ} \mathrm{C}, 45\right.$ $\mathrm{sec})$, and extension $\left(72^{\circ} \mathrm{C}, 1 \mathrm{~min}\right)$. Subsequently, the material was maintained at $72^{\circ} \mathrm{C}$ for $10 \mathrm{~min}$, and the amplified product was stored at $4^{\circ} \mathrm{C}$ until analysis. Amplification was carried out on an automatic MJ MiniOpticon ${ }^{\text {TM }}$ Real-Time PCR System (BioRad).

The electrophoresis was performed according to the method of Sambrook et al. ${ }^{18-20}$ using $2 \%$ agarose gel. The amplification products were detected using 1:5 ratio of the amplified reaction mixture with $1 \mu \mathrm{L}$ GelRed (Nucleic Gel Stain, BioAmerica, Inc.) and visualized under ultraviolet light. A ladder with fragments of known molecular weight was used as a marker (100-pb ladder/ Sharp DNA Marker, RBC). The samples presenting a 779-bp amplicon were considered positive for GBS.

\section{Statistical analysis}

The sensitivity, specificity, positive predictive value (PPV), and negative predictive value (NPV) of the PCR technique were calculated using the culture method as the gold standard. Concordance between assays was determined using the Kappa coefficient $(\mathrm{k})^{21}$. Statistical analyses were performed using Statistical Package for the Social Sciences $\left(\right.$ SPSS $\left.^{\circledR}\right)$ v.21.0 software (SPSS Statistics, Inc., Chicago, IL, USA).

\section{RESULTS}

The sociodemographic and clinical characteristics of the 204 pregnant women screened for vaginal and/or perianal GBS colonization in this study are summarized in Table 1. The following individual characteristics and unfavorable sociodemographic conditions were observed: ages below 17 years or above 35 years in $27.2 \%$ of cases; low level of education in $37.7 \%$ of cases; and legal or illegal drug addiction in $17.6 \%$ of cases. Abortions, nulliparity, and multiparity were observed in $15.2 \%, 26.5 \%$, and $25 \%$ of the patients, respectively. The main factors associated with clinical intercurrences were arterial hypertension (50.5\%) and diabetes mellitus (29.9\%).

When combining the vaginal and perianal samples, PCR analysis detected GBS in a higher number of patient samples $(53 ; 26 \%)$ than the culture method $(46 ; 22.5 \%)$. Notably, lower rates of GBS colonization were observed in vaginal samples alone, compared to the respective perianal samples, by both methodologies (Table 2). Lastly, the culture method involving application of the CAMP test immediately after growth in ToddHewitt selective enrichment broth, without previous colony isolation, detected GBS in $19.6 \%(n=40)$ of the patients. All culture-positive samples were also positive by PCR analysis, indicating $100 \%$ sensitivity for this test. Meanwhile, of the 158 culture-negative samples, seven tested positive for GBS by PCR; the remaining 151 were negative. As such, the specificity of the PCR method was $95.6 \%$. The PPV and NPV were $86.8 \%$ and $100 \%$, respectively (Table 3 ). The Kappa coefficient for the two methods was 0.907 (0.811-0.907), indicating substantial agreement beyond chance.

\section{DISCUSSION}

Investigation of GBS colonization during pregnancy has attracted much interest, as exposure to bacteria that colonize the maternal genital and/or gastrointestinal tracts or infect the urinary tract are the primary causes of GBS neonatal disease ${ }^{2}$.

While the Brazilian Medical Guidelines recommend GBS screening during prenatal care ${ }^{22}$, no official Brazilian governmental guidelines regarding GBS in pregnant women have been established. In contrast, such guidelines have been in place in North America and certain European countries 
TABLE 1

Sociodemographic and clinical characteristics of the 204 pregnant women recruited for this study at Caxias do Sul General Hospital, Brazil.

\begin{tabular}{|c|c|}
\hline Characteristics & Number (Percentage) \\
\hline \multicolumn{2}{|l|}{ Sociodemographic } \\
\hline \multicolumn{2}{|l|}{ Occupation } \\
\hline exposure to physical, chemical, and biological agents & $46(22.5)$ \\
\hline housemaid & $10(4.9)$ \\
\hline other & $37(18.1)$ \\
\hline \multicolumn{2}{|l|}{ Previous reproductive history } \\
\hline Perinatal death & $6(2.9)$ \\
\hline Premature or malformed newborn & $12(5.9)$ \\
\hline Abortion & $31(15.2)$ \\
\hline Nulliparity & $54(26.5)$ \\
\hline Multiparity ( $>3$ children) & $51(25.0)$ \\
\hline \multicolumn{2}{|l|}{ Clinical intercurrences } \\
\hline IUGR, fetus number and amniotic fluid volume & $6(2.9)$ \\
\hline Blood disorders & $6(2.9)$ \\
\hline Urinary tract infection & $4(2.0)$ \\
\hline Fetal malformation & $4(2.0)$ \\
\hline Heart disease & $3(1.5)$ \\
\hline Abortion threat & $3(1.5)$ \\
\hline Placenta previa & $1(0.5)$ \\
\hline Other $^{3}$ & $18(8.8)$ \\
\hline
\end{tabular}

IUGR: intra-uterine growth restriction; HIV: human immunodeficiency virus. *Variable with incomplete data. ${ }^{1}$ Diabetes mellitus $(\mathrm{n}=21)$; gestational diabetes mellitus $(\mathrm{n}=40)$; hypothyroidism $(\mathrm{n}=2)$. ${ }^{2} \mathrm{HIV}(\mathrm{n}=9)$; toxoplasmosis $(\mathrm{n}=5)$; syphilis $(\mathrm{n}=2)$; varicella $(\mathrm{n}=1)$. ${ }^{3}$ Poor obstetric history $(\mathrm{n}=11)$; psychopathy $(n=2)$; depression $(n=2)$; ovarian cyst $(n=1)$; brain aneurysm $(n=1)$; seizure $(n=1)$.

TABLE 2

Prevalence of Group B Streptococcus (GBS) colonization in 204 pregnant women, as determined by culture and PCR-based detection methods.

\begin{tabular}{lccc}
\hline \multirow{3}{*}{ Methods } & \multicolumn{3}{c}{ Colonization* } \\
\cline { 2 - 4 } & $\begin{array}{c}\text { vaginal } \\
\mathbf{n}(\%)\end{array}$ & $\begin{array}{c}\text { perianal } \\
\mathbf{n}(\%)\end{array}$ & $\begin{array}{c}\text { vaginal/perianal } \\
\mathbf{n}(\%)\end{array}$ \\
\hline Culture & $38(18.6)$ & $36(17.6)$ & $46(22.5)$ \\
PCR & $44(21.6)$ & $39(19.1)$ & $53(26.0)$ \\
\hline
\end{tabular}

PCR: polymerase chain reaction. *Number and \% of GBS-positive patients.

for more than a decade. In previous studies, the prevalence indexes for GBS in Brazil (14.6\% to $32.6 \%)^{13-17}$ were similar to those in countries that have adopted universal laboratory screening and maternal intrapartum antibiotic prophylaxis ( $10 \%$ to $30 \%)$; however, these values could potentially vary greatly by geographic location, sociodemographic and clinical characteristics, and the detection technique employed. Regardless, the colonization rates observed in this study $(22.5 \%$ to $26 \%$ ) are consistent with those detected worldwide $2,6,8,14,16,18,20$.

Studies investigating GBS in vaginal samples alone detected prevalence rates ranging between $11 \%$ and $19.8 \%$, whereas
TABLE 3

Sensitivity, specificity, and predictive values for the PCR assay for detection of Group B Streptococcus (GBS) in the cohort of 204 pregnant women.

\begin{tabular}{lc}
\hline Performance & Percentage (95\% CI) \\
\hline Sensitivity & $100.0(92.2-100.0)$ \\
Specificity & $95.6(93.3-95.6)$ \\
Positive predictive value (PPV) & $86.8(80.0-86.8)$ \\
Negative predictive value (NPV) & $100.0(97.6-100.0)$
\end{tabular}

PCR: polymerase chain reaction; CI: confidence interval.

recto-vaginal cultures reveal higher colonization rates, varying between $22 \%$ and $29.5 \% \%^{8,23-25}$. In this study, the GBS isolation rates increased by $18.4 \%$ and $20.5 \%$ for the culture and PCR methods, respectively, when perianal samples were included in the analysis. Both vaginal and perianal swabbing increased the culture yield substantially, compared with sampling the vagina without including swabbing of the perianal region. As with culturing, it remained important to collect a vaginal-perianal sample for accurate PCR-based detection of GBS.

Accurate identification of GBS colonization is a crucial component of laboratory screening of pregnant women to 
determine eligibility for intrapartum antibiotic prophylaxis. Therefore, an optimal screening test should exhibit high sensitivity and negative predictive values. Ideal testing should also detect GBS at birth as accurately and quickly as possible, even when births are premature, as maternal colonization can be transitory, chronic, or intermittent. Both traditional and real-time PCR techniques have been widely investigated in this context ${ }^{8,18,26-28}$. In this study, both the sensitivity and NPV of the molecular method were $100 \%$, respectively. The same values were observed in similar study, reported by De Paris et al. ${ }^{18}$. The high sensitivity of the PCR method could be related to the use of clinical sample enrichment media prior to the analysis. Meanwhile, the high NPV is a critical result because it rules out the possibility of false-negatives, and therefore provides definitive evidence of which mothers do not require prophylactic therapy. For comparison, while culture is considered the gold standard for GBS diagnosis, this method can yield false negative results due to excessive growth of microbiota-derived organisms, which can inhibit the growth of GBS, the inability of the culture to detect small bacterial colonies, or the use of antibiotics. Since PCR detects only bacterial genes, not viable bacteria colonies, this can enhance the PPV of the test. In our study, the PPV was $86.8 \%$, which was markedly higher than those observed in similar studies conducted by De Paris et al. ${ }^{18}$ (59\%) and Bidgani ${ }^{28}(52.0-68.0 \%)$.

Lastly, of the tests screened in this work, culture combined with the CAMP test exhibited the lowest detection rate (19.6\%). However, advantages of this approach include the ease of execution, the ability to streak several clinical samples on a single sheep blood agar plate, and a one-day reduction in obtaining results compared to the culture method. Moreover, the CAMP test is known for its usefulness in identifying GBS isolates, $96.0 \%$ to $99.0 \%$ of which test positive by this method $^{17}$.

In conclusion, our results show that PCR comprises a fast screening method and an efficient diagnostic tool for GBS that can be utilized to identify pregnant mothers that require prophylactic treatment, and thereby prevent transfer of the organism to the newborn. However, the routine implementation of this approach in the clinical setting will be dependent on site-by-site analyses of its cost-effectiveness.

\section{Acknowledgments}

The authors are grateful to Dr. Ricardo da Silva de Sousa (in memoriam) Laboratório de Pesquisa em HIV/AIDS, Universidade de Caxias do Sul, RS, Brasil.

\section{Conflict of interest}

The authors declare that there is no conflict of interest.

\section{REFERENCES}

1. Centers for Disease Control and Prevention (CDC). Prevention of Perinatal Group B Streptococcal Disease: a Public Health Perspective. MMWR Recomm Rep. 1996;45(RR7):1-24.

2. Centers for Disease Control and Prevention (CDC). Prevention of Perinatal Group B Streptococcal Disease: revised guidelines from CDC, 2010. MMWR Recomm Rep. 2010;59(RR10):1-32.
3. The American College of Obstetricians and Gynecologists (ACOG). Prevention of early-onset group B streptococcal disease in newborns. Committee on Obstetric Practice. Number 173, June 1996. Int J Gynaecol Obstet. 1996;54(2):197-205.

4. American Academy of Pediatrics (AAP). Revised guidelines for prevention of early-onset group B streptococcal (GBS) infection. Committee on Infectious Diseases and Committee on Fetus and Newborn. Pediatrics. 1997;99(3):489-96.

5. Centers for Disease Control and Prevention (CDC). Prevention of perinatal group B streptococcal disease: revised guidelines from CDC. MMWR Recomm Rep. 2002; 51(RR11):1-22.

6. Barcaite E, Bartusevicius A, Tameliene R, Kliucinskas M, Maleckiene L, Nadisauskiene R. Prevalence of maternal group B streptococcal colonization in European countries. Acta Obstet Gynecol Scand. 2008;87(3):260-71.

7. Khan MA, Faiz A, Ashshi AM. Maternal colonization of group B streptococcus: prevalence, associated factors and antimicrobial resistance. Ann Saudi Med. 2015;35(6):423-7.

8. Bergeron MG, Ke D, Ménard C, Picard FJ, Gagnon M, Bernier M, et al. Rapid detection of group B streptococci in pregnant women at delivery. N Engl J Med. 2000;343(3):175-9.

9. Kwatra G, Adrian PV, Shiri T, Buchmann EJ, Cutland CL, Madhi SA. Serotype-Specific Acquisition and Loss of Group B Streptococcus Recto-Vaginal Colonization in Late Pregnancy. Plos One. 2014;9(6):e98778.

10. Simões JA, Alves VMN, Fracalanzza SEL, Camargo RPS, Mathias L, Milanez HMBP, et al. Phenotypical characteristics of group B Streptococcus in parturients. Braz J Infect Dis. 2007;11:261-6.

11. Rocchetti TT, Marconi C, Rall VLM, Borges VTM, Corrente JE, da Silva MG. Group B streptococci colonization in pregnant women: risk factors and evaluation of the vaginal flora. Arch Gynecol Obstet. 2011;283(4):717-21.

12. Nomura ML, Passini Júnior JR, Oliveira UM. Selective versus nonselective culture medium for group B Streptococcus detection in pregnancies complicated by preterm labor or preterm-premature rupture of membranes. Braz J Infect Dis. 2006;10(4):247-50.

13. Castellano-Filho DS, Silva VL, Nascimento TC, Vieira MT, Diniz CG. Detection of Group B Streptococcus in Brazilian pregnant women and antimicrobial susceptibility patterns. Braz J Microbiol. 2010;41(4):1047-55.

14. Díaz TM, Nieves BM. Comparison between culture media and procedures to detect Streptococcus agalactiae in pregnant women. Rev Chil Infectol. 2008;25(2):108-13.

15. Collins TS, Calderon M, Gilman RH, Vivar A, Charache P. Group B streptococcal colonization in a developing country: its association with sexually transmitted disease and socioeconomic factors. Am J Trop Med Hyg. 1998;59(4):633-6.

16. Larcher JS, Capellino F, De Giusto R, Travella C, Balangione FG, Kreiker G, et al. Group B Streptococcus colonization during pregnancy and prevention of early onset of disease. Medicina (B Aires). 2005;65(3):201-6.

17. Phillips EA, Tapsall JW, Smith DD. Rapid tube CAMP test for identification of Streptococcus agalactiae (Lancefield group B). J Clin Microbiol. 1980;12(2):135-7.

18. De-Paris F, Machado ABMP, Gneno TC, Ascoli BM, Oliveira KRP, Barth AL. Group B Streptococcus detection: comparison of PCR assay and culture as a screening method for pregnant women. Braz J Infect Dis. 2011;15(4):323-7.

19. Sambrook J, Fritsch EF, Maniatis T. Molecular cloning: a Laboratory Manual. 2nd edition. New York: Cold Spring Harbor Laboratory Press. 1989. 1126 p. 
20. Munari FM, De-Paris F, Salton GD, Lora PS, Giovanella P, Machado ABMP, et al. A combined enrichment/polymerase chain reaction based method for the routine screening of Streptococcus agalactiae in pregnant women. Braz J Microbiol. 2012;43(1):253-260.

21. Rosner BR. Fundamentals of Biostatistics. 7th edition. Boston: Brooks Cole; 2011.

22. Melo VH, Pires do Rio SM. Assistência Pré-natal. Available at: http://www. projetodiretrizes.org.br/5_volume/02-AssistPre.pdf. Accessed 15 July 2015.

23. Costa NDVL, Carvalho M, Pone SM, G Júnior SC. Gestantes colonizadas pelo Streptococcus do grupo B e seus recém-nascidos: análise crítica da conduta adotada no Instituto Fernandes Figueira, Fundação Oswaldo Cruz. Rev Paul Pediatr. 2010;28(2):155-61.

24. Quinlan JD, Hill DA, Maxwell BD, Boone S, Hoover F, Lense JJ. The necessity of both anorectal and vaginal cultures for group B Streptococcus screening during pregnancy. J Fam Pract. 2000;49(5):447-8.
25. El Aila NA, Tency I, Claeys G, Saerens B, Cools P, Verstraelen H, et al. Comparison of different sampling techniques and of different culture methods for detection of group B Streptococcus carriage in pregnant women. BMC Infect Dis. Available at: http://www. biomedcentral.com/1471-2334/10/285; 2010. Accessed 2 August 2011.

26. Clarke C, O'Connor L, Carré-Skinner H, Piepenburg O, Smith TJ. Development and performance evaluation of a recombinase polymerase amplification assay for the rapid detection of group B streptococcus. BMC Microbiol. 2016;16(1):221.

27. Mousavi SM, Hosseini SM, Mashouf RY, Arabestani MR. Identification of Group B Streptococci Using 16S rRNA, cfb, $\mathrm{scpB}$, and atr Genes in Pregnant Women by PCR. Acta Med Iran. 2016;54(12):765-70.

28. Bidgani SA, Navidifar TA, Najafian MB, Amin MA. Comparison of group B streptococci colonization in vaginal and rectal specimens by culture method and polymerase chain reaction technique. J Chin Med Assoc. 2016;79(3):141-5. 